\title{
SIMULASI PERJALANAN AMPLOP BERKAS AKSELERATOR ION ENERGI MEDIUM
}

\author{
Sigit Hariyanto, Slamet Santosa \\ Pusat Penelitian dan Pengembangan Teknologi Maju - BATAN \\ Jl. Babarsari Kotak Pos 6101 ykbb, Yogyakarta 55281
}

\begin{abstract}
ABSTRAK
SIMULASI PERJALANAN AMPLOP BERKAS AKSELERATOR ION ENERGI MEDIUM. Telah dilakukan simulasi transpor berkas ion energi menengah (tandem) dengan program partikel berkas optik laboratory versi 1.1.1. Berkas ion yang dipercepat adalah ion hidrogen dan nitrogen, ke luar dari sumber ion SNICS dengan inisial jejari ke arah X dan Y masing-masing $1 \mathrm{~cm}$ dan sudut emitansi ke arah horisontal dan vertikal masing-masing 16,4 $\pi \mathrm{mm} \mathrm{mRad}$. Simulasi dilakukan dua kali yaitu pada pemercepat energi rendah untuk ion negatif dan pada pemercepat energi menengah untuk ion positif. Untuk membatasi jejari amplop berkas pada hasil simulasi energi rendah digunakan program fitting dengan empat buah lensa einzel, dua buah magnet pembelok dan sebuah kuadrupol elektrostatis. Untuk lensa einzel pertama diperoleh panjang fokus $70 \mathrm{~cm}$, medan magnet pembelok $3,378 \mathrm{kG}$, sudut pembelokan $30^{\circ}$, Untuk lensa einzel kedua diperoleh panjang fokus $24 \mathrm{~cm}$, pembelokan beam dengan sudut $90^{\circ}$, diperoleh medan magnet pembelok 3,89 kG dan diperoleh jejari kelengkungan 0,457 m. Setelah keluar, masuk lensa einzel dengan panjang fokus $30 \mathrm{~cm}$ dan difokuskan oleh kuadrupol listrik dengan koefisien kuadrupol 54,25 dan -89,51 dan panjang elektroda $0,07 \mathrm{~m}$. Sebelum masuk ke tabung pemercepat, dilewatkan lensa einzel dengan panjang fokus $26 \mathrm{~cm}$. Untuk mempercepat ion positif pada simulasi transport berkas pada energi medium digunakan tabung akselerator dengan tegangan pemercepat -15 MV, kemudian berkas elektron dilewatkan pada magnet pembelok dan magnet kuadrupol. Traspor berkas dengan metode fitting mendapatkan pembelok magnet $15^{\circ}$ dan kuat medan magnet 3,997 kG. Sedangkan pada panjang elektrode kuadrupol magnet doblet 0,14 m didapatkan kuat medan magnet $3,2 \mathrm{kG}$ dan $-3,4 \mathrm{kG}$.
\end{abstract}

\section{ABSTRACT}

SIMULATION OF BEAM ENVELOP TRANSPORT IN MEDIUM ENERGY OF ION ACCELERATOR. Simulation of beam envelop transport in medium energy of ion accelerator (Tandem) using beam particle optic laboratory program of version 1.1.1 has been carried out. The accelerated ion beam are hydrogen and nitrogen ion, which leave the SNICS ion source within $X$ and $Y$ direction of initial radius of $1 \mathrm{~cm}$ respectively and having vertical and horizontal degree of emittance of 16,4 $\pi \mathrm{mm}$ mRad respectively. The simulation is completed twice, i.e. for negative ion is made on low energy of accelerator and for positive ion is arranged on medium energy of accelerator. To keep the beam envelop radius of simulation result of low energy simulation, the fitting program is used with four einzel lenses, two bending magnet and one electrostatic quadrupole. On the first einzel lens the obtained focus length is $70 \mathrm{~cm}$, the bending magnetic field as $3.378 \mathrm{kG}$, the angle of bending as $30^{\circ}$ and the curvature radius as $0.533 \mathrm{~m}$. On the second einzel lens the obtained focus length is $24 \mathrm{~cm}$ with bending beam angle as $90^{\circ}$, the bending magnetic field obtained as $3.89 \mathrm{kG}$ and the obtained curvature radius is $0.457 \mathrm{~m}$. The beam envelop is then entered into einzel lens with focus length of $30 \mathrm{~cm}$ and it then focused by using electrostatic quadrupole with coefficient quadrupole 54.25 and -89.51 and electrode length of $0.07 \mathrm{~m}$. Before the beam envelop entered accelerator tube, it pass the einzel lens with focus length of $26 \mathrm{~cm}$. To accelerate positive ion of the beam envelop simulation at medium energy the $-1.5 \mathrm{MV}$ voltage of accelerator tube is used, then the beam passes through a bending magnet and a magnetic quadrupole. Beam envelop transport by using fitting method obtained a bending magnet $15^{\circ}$ and a magnetic field strength 3.997 $k G$. While at the electrode length of $0.14 \mathrm{~m}$ of quadrupole magnetic doublet, it was obtained the magnetic field strengths of $3.2 \mathrm{kG}$ and $-3.4 \mathrm{kG}$

\section{PENDAHULUAN}

Q ampai sekarang P3TM masih merencanakan program instalasi laboratorium berbasis akselerator. Bagian pokok instalasi tersebut adalah akselerator energi medium (tandem) dengan tegangan pemercepat 1,5 MV, yang diharapkan dapat menyediakan berkas ion proton dengan energi medium, dan kualitas berkas cukup stabil untuk analisis suatu bahan dengan metode PIXE, RBS, NRA dan eksperimen di bidang fisika, kimia, kedokteran dan lingkungan ${ }^{[1]}$. Untuk keperluan tersebut, diperlukan sistem perencanaan penempatan dan besarnya parameter transportasi berkas ion dari sumber ion ke pemercepat kemudian ke tempat target dimana 
eksperimen dilakukan. Peralatan/komponen akselerator untuk transpor berkas dan penempatan perencanaan seperti lensa elektrostatis (lensa einzel), lensa pemokus baik elektrostatik maupun magnet, magnet pembelok atau defektor, tabung hanyut dan sebagainya. Perencanaan memerlukan perhitungan simulasi keadaan/kualitas berkas sepanjang perjalanan ion, sehingga dapat mencapai target di tempat eksperimen pada keadaan yang diinginkan tidak mengalami tumbukan dengan dinding peralatan sistem transportasi.

Dalam makalah ini dilaporkan hasil simulasi untuk berkas ion $\mathrm{H}^{+}$dan $\mathrm{N}^{+}$yang dipercepat 1,5 MV dari sumber ion negatif dan percepatan awal $25 \mathrm{kV}$. Pada akselerator tandem $1,5 \mathrm{M}$, energi ion yang dihasilkan $\mathrm{H}^{+}$ mencapai $3 \mathrm{MeV}$, tetapi untuk jenis ion dengan charge state lebih tinggi, energi yang dihasilkan lebih besar. Untuk simulasi transportasi berkas dipisah menjadi dua bagian yaitu pada percepatan energi rendah dan energi medium. Pada energi rendah simulasi dilakukan mulai dari sumber ion, pembelok, pemercepat sampai ke stripper dengan mempercepat ion negatif. Sedangkan pada bagian selanjutnya dilakukan simulasi dari sistem stripper, pemercepat energi medium, pembelok sampai ke target dengan mempercepat ion positif. Simulasi ini digunakan model tata letak akselerator tandem dari perusahaan NEC (National Electrostatic Corporation). Program yang digunakan dalam simulasi perjalanan amplop berkas akselerator ion menggunakan program PBO (Particle Beam Optics) version 1.1.1. untuk Microsoft windows 95/98 yang menggunakan kode tentang peralatan akselerator antara lain; lensa einzel, sistem pemokus elektrostatis/magnet, pembelok, pemercepat dan lainnya.

\section{DASAR TEORI}

Suatu berkas partikel yang bergerak dalam garis tranportasi berkas melalui sistem statis maupun sistem medan magnet maupun elektrostatis dapat disederhanakan dengan proses perkalian matriks.

$$
X(1)=R X(0)
$$

Subskrip 0 dan 1 menunjukkan masuk dan keluarnya berkas ke masing-masing peralatan atau komponen sistem akselerator. $R$ adalah matriks pengiriman (matrix $\mathrm{R}$ ) dengan elemen $6 \times 6$ untuk orde pertama, merupakan persamaan gerak partikel yang melalui peralatan atau komponen akselerator. Beberapa komponen akselerator yang digunakan untuk eksperimen antara lain: tabung hanyut, lensa lensa pemokus, pembelok magnet, kuadrupol magnet dan sebagainya. Secara umum matriks $\mathrm{R}$ untuk semua komponen akselerator merupakan perkalian masing-masing matriks ${ }^{[2]}$;

$$
\text { Rtotal }=R(n) \ldots \ldots R(3) R(2) R(1)
$$

Dengan $R(n)$......R(3) $R(2) R(1)$ = matriks pengirim dari komponen akselerator antara lain : lensa einzel, sistem pemokus, pemercepat, magnet pembelok dan sebagainya.

Berkas partikel dalam garis perjalanan kalau diproyeksikan ke bidang horisontal maupun vertikal berbentuk elips dengan arah yang berbeda. Teorema Liouville sangat berguna untuk menggambarkan berkas dalam ruang fase. Bila kita tahu luas yang diduduki oleh partikel-partikel dalam ruang fase pada awal dari garis peralanan berkas, maka kita dapat menentukan lokasi dan distribusi berkas pada tiap tempat yang lain sepanjang garis perjalanan, tanpa harus menghitung trayektory dari masing-masing partikel . Elips yang membatasi semua partikel dari berkas dalam ruang fase disebut elips fase.

Persamaan elips dalam dimensi n dituliskan dalam bentuk matriks sebagai berikut ${ }^{[2,3]}$ :

$$
X(0)^{T} \sigma(0)^{-1} X(0)=1
$$

Dengan $X(0)^{T}$ adalah tranpose dari koordinat vektor matriks kolom berkas $X(0)$ dan $\sigma(0)$ matriks simetri merupakan bilangan nyata positif, kalau dituliskan dalam 2 dimensi $\left(x, x^{\prime}\right)$ arah horizontal matriks $\sigma$ :

dengan $\varepsilon_{\mathrm{x}}^{2}=$ determinan $\sigma$

$$
\sigma=\left[\begin{array}{ll}
\sigma_{11} & \sigma_{21} \\
\sigma_{21} & \sigma_{22}
\end{array}\right] \text { inversnya } \sigma^{-1}=1 / \varepsilon_{x}^{2}\left[\begin{array}{ll}
\sigma_{22} & \sigma_{21} \\
\sigma_{21} & \sigma_{11}
\end{array}\right]
$$

matriks kolom berkas : 


$$
X=\left[\begin{array}{c}
x \\
x^{\prime}
\end{array}\right] \text { dan } X^{T}=\left\{x \cdots x^{\prime}\right\}
$$

Penjabaran persamaan matriks $X^{\top} \sigma^{-1} X=1$ adalah bentuk persamaan elips :

$$
\sigma_{22} X^{2}-2 \sigma_{21} X^{\prime}+\sigma_{11} X^{\prime 2}=\varepsilon_{x}^{2}=\operatorname{det} \sigma
$$

Luas elips adalah :

$A=\pi \varepsilon_{x}=\pi(\operatorname{det} \sigma)^{1 / 2}=\pi X_{\text {mak }} X_{\text {int }}=\pi X_{\text {int }} X_{\text {mak }}, \varepsilon_{x}=$ emitansi

Elips fase pada bidang $(X, X)$ ditunjukkan pada Gambar 1, dengan masing-masing elemen matriks $\sigma$.

Orientasi dari elips adalah korelasi antara $X$ dan $X$, yang besarnya tergantung $\sigma_{i i}$

$$
r_{12}=r_{21}=\frac{\sigma_{21}}{\sqrt{\left(\sigma_{11} \sigma_{22}\right)}}
$$

berkas partikel atau amplop berkas setelah melalui sistem komponen akselerator, transformasi berkas matriksnya ditunjukkan pada persamaan 1 . Kombinasi matriks tersebut dengan persamaan berkas matriks elips, dan dengan menggunakan matriks satuan $R R^{-1}=$ I, diperoleh elips baru setelah transformasi menjadi :

$$
X(1)^{T} \sigma(1)^{-1} X(1)=1
$$

dengan: $\sigma(1)=R \sigma(0) R^{T}$

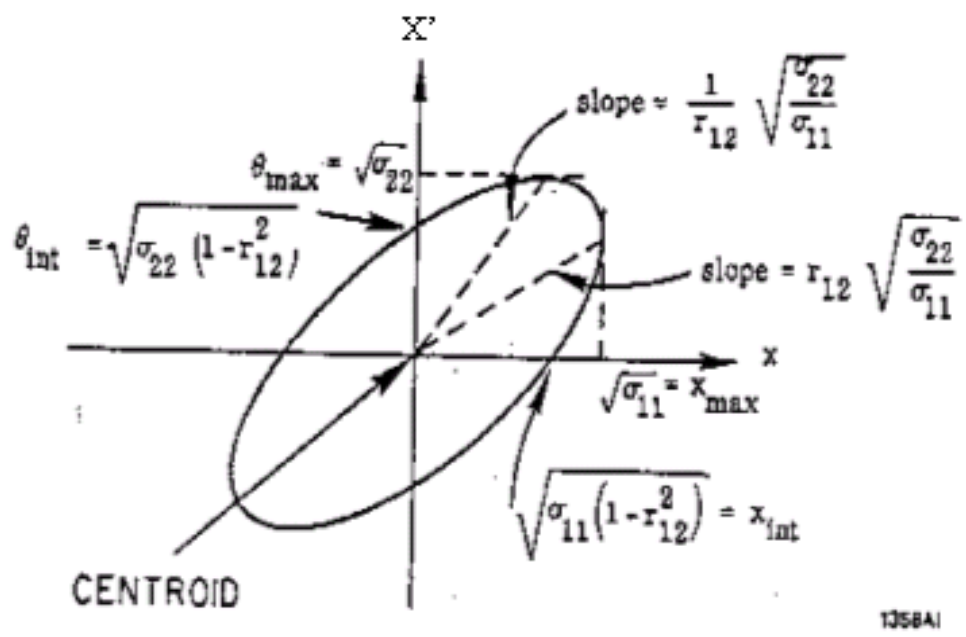

Gambar 1. Elips fase pada bidang $(X, X)$.

Persamaan di atas merupakan matriks sigma pada ujung garis transport berkas dihubungkan dengan awal bidang berkas.

Arti dari elemen matriks $\sqrt{\sigma_{i i}}$ sebagai berikut :

$\sigma_{11}=X_{\text {mak }}=$ setengah lebar maksimum amplop berkas pada bidang $X$.

$\overline{\sigma_{22}}=X=$ setengah sudut divergensi amplop berkas pada bidang $X$.

Amplop berkas partikel di dalam transport berkas proyeksinya merupakan bentuk elips, dapat juga dituliskan dalam bentuk parameter Twiss $\alpha, \beta, \gamma$

$$
\gamma_{x} x^{2}+2 \alpha_{x} x x^{\prime}+\beta_{x} x^{2}=\varepsilon_{x}
$$

masing masing elemen pada persamaan elips di atas dapat dinyatakan dalam bentuk matriks sigma dengan,

$$
\nu_{x}=\sigma_{22} / \varepsilon_{x}, \beta_{x}=\sigma_{11} / \varepsilon_{x}, a_{x}=-\sigma_{12} / \varepsilon_{x}
$$


Parameter twiss alfa, beta, dan gamma juga merupakan parameter courant-syder, pada Gambar 2 ditunjukkan elip fase pada bidang horisontal dengan twiss parameter yang merupakan penggambaran amplop berkas dalam akselerator.

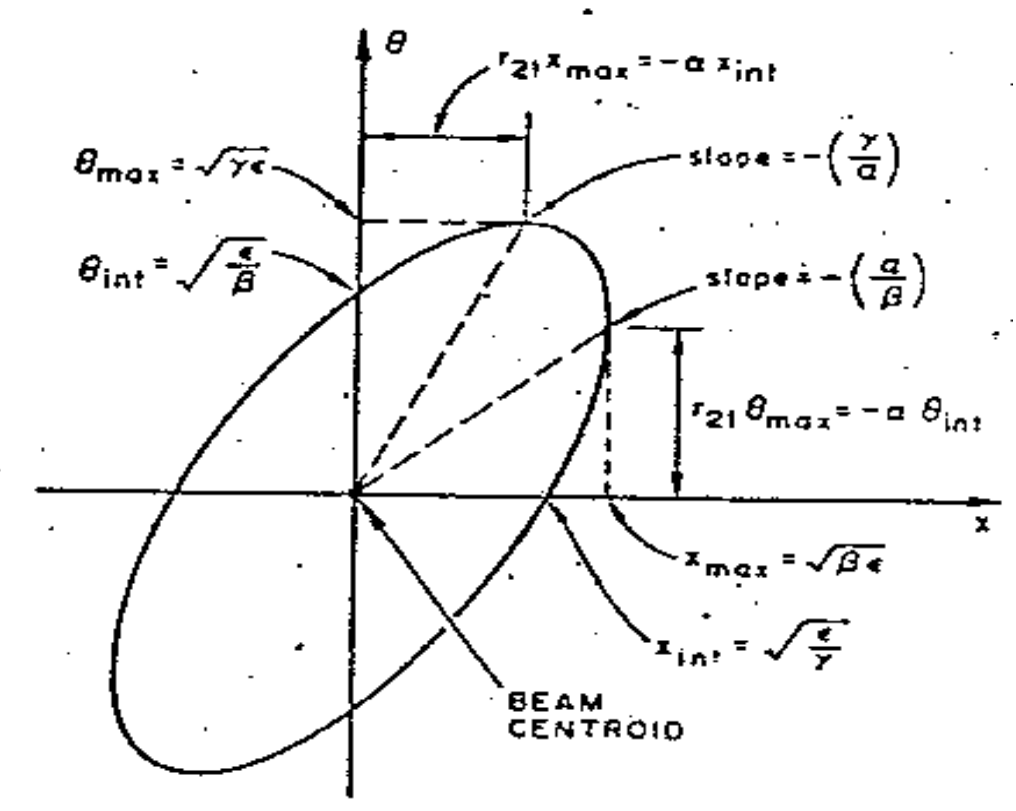

Gambar 2. Fase elip dengan twiss parameter.

\section{METODOLOGI}

Transportasi berkas ion yang akan disimulasikan dengan program PBO (particle beam optik) berdasar tata letak akselerator tandem 1,5 MV seperti ditunjukkan pada Gambar 3. Sumber ion SNICS dari akselerator tandem menghasilkan ion negatif diekstrak dengan tegangan $15 \mathrm{kV}$ diarahkan dengan lensa einzel ke pembelok magnet $30^{\circ}$ sebagai pemilih ion negatif, kemudian difokuskan lagi dengan lensa einzel sebelum dibelokkan pembelok magnet $90^{\circ}$ sebagai pengarah ke sistem pemercepat ion negatif.

Keluar dari pembelok magnet, diameter amplop berkas sudah menjadi besar lagi, maka perlu dijaga ruji ke arah horisontal maupun vertikal dengan diberi lensa einzel, sistem pemokus kuadrupole elektrostatis, lensa einzel sebelum masuk tabung pemercepat yang diberi tegangan pemercepat 1,5 MV. Pada energi ion $>1,5$ $\mathrm{MeV}$ ditumbukkan ke stripper dari gas nitrogen, sehingga terjadi pelucutan elektron dan terjadi perubahan muatan menjadi ion positif dengan berbagai charge state. Ion positif ini dipercepat lagi oleh pemercepat kedua dengan tegangan $-1,5 \mathrm{MV}$, dan dihasilkan energi ion $3 \mathrm{MeV}$ untuk proton tetapi untuk ion dengan charge state lebih besar diperoleh energi lebih besar.

Dalam mensimulasi perjalanan berkas digunakan program fitting untuk membatasi ruji amplop berkas pada tempat tertentu. Ukuran komponen akselerator mengambil data panjang dari akselerator tandem $5 \mathrm{SDH}$ akselerator peletron, yaitu 1,5 m pemercepat ion negatif, tabung stripper dari gas nitrogen sepanjang $0,3 \mathrm{~m}$ dan $1,5 \mathrm{~m}$ pemercepat ion positif. Akselerator tandem yang akan disimulasi mempunyai terminal dengan jangkauan tegangan antara 0,05-1,7 MV. Untuk mengarahkan ke magnet pembelok digunakan lensa einzel EL44-20 dengan apertur $44,5 \mathrm{~mm}$ tegangan mencapai $25 \mathrm{kV}$. Sedangkan untuk mengarahkan ke tabung pemercepat digunakan lensa kuadrupol elektrostatis doblet EQT 38-60 dengan panjang elemen $7 \mathrm{~cm}$, apertur $3,8 \mathrm{~cm}$. Semua komponen akselerator di atas yang akan disimulasikan merupakan penawaran dari NEC. 


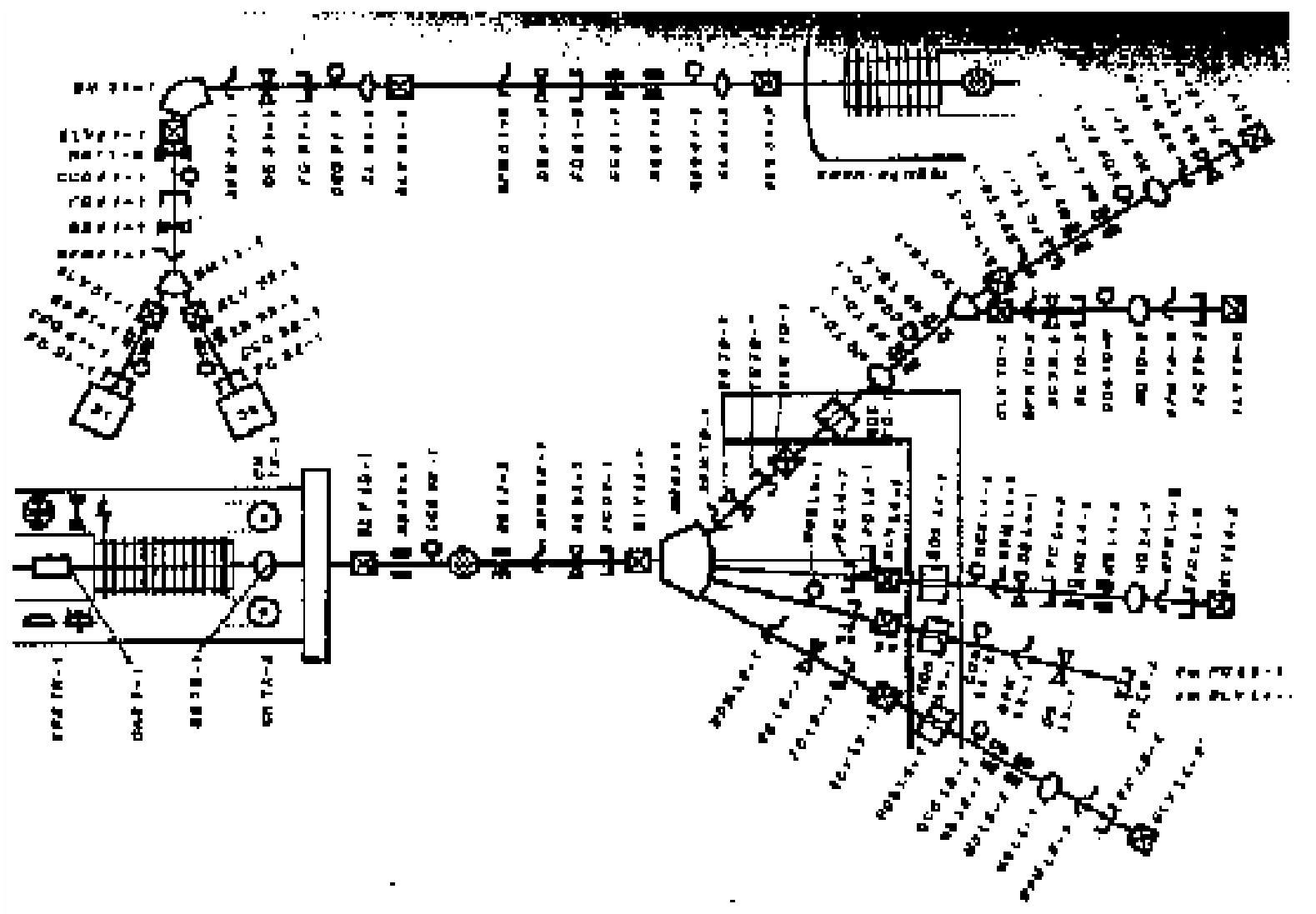

Gambar 3. Tata letak akselerator tandem 1,5 MV.

\section{HASIL DAN PEMBAHASAN}

Hasil simulasi akselerator tandem 1,5 MV dengan menggunakan ion hidrogen yang menggunakan program PBO ditunjukkan pada Gambar 4.

Pada simulasi ini dibagi menjadi dua daerah yaitu pada bagian energi rendah yang dipercepat hanya ion negatif sebelum melewati stripper, sedangkan bagian kedua setelah mengalami pelepasan elektron sehingga menjadi ion positif dan dipercepat lagi. Dari gambar di atas terlihat perjalanan amplop berkas mulai dari sumber ion hidrogen melalui peralatan akselerator lensa einsel, pembelok magnit, pemercepat sampai ke target. Secara menyeluruh amplop berkas setelah keluar sumber ion SI langsung difokuskan oleh lensa einsel $\mathrm{LE}_{1}$ melalui tabung hanyut $\mathrm{TH}_{1}$, pembelok magnit $\mathrm{BM}_{1}$ dan seterusnya sampai ke pemercepat ion negatif PIN. Ruji amplop ke arah horisontal maupun vertikal dari gambar terlihat masih terjaga tidak melebihi diameter dinding tabung hanyut yang besarnya $5 \mathrm{~cm}$.

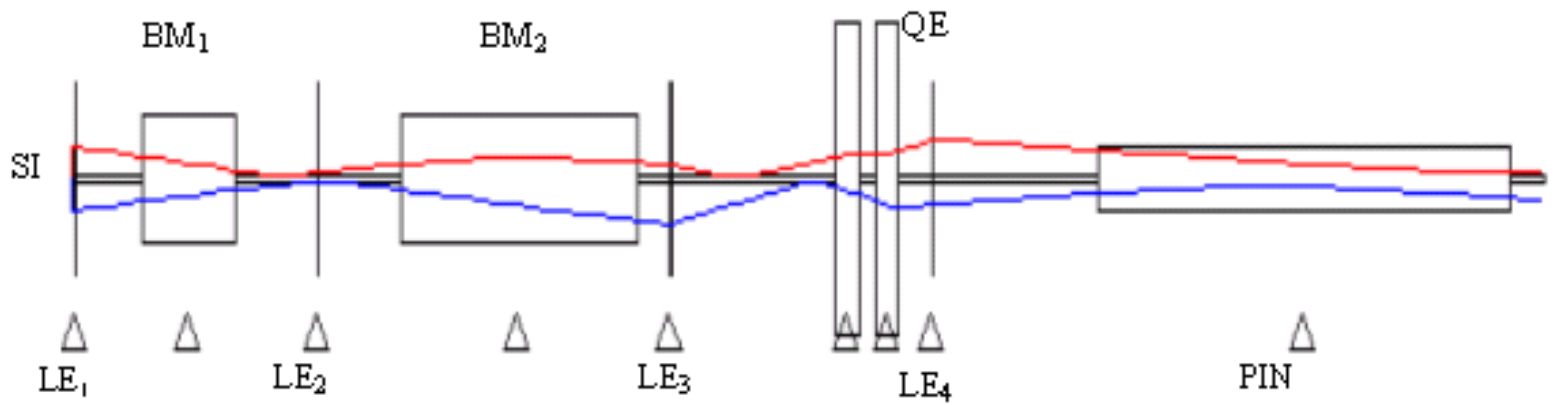

(a) 


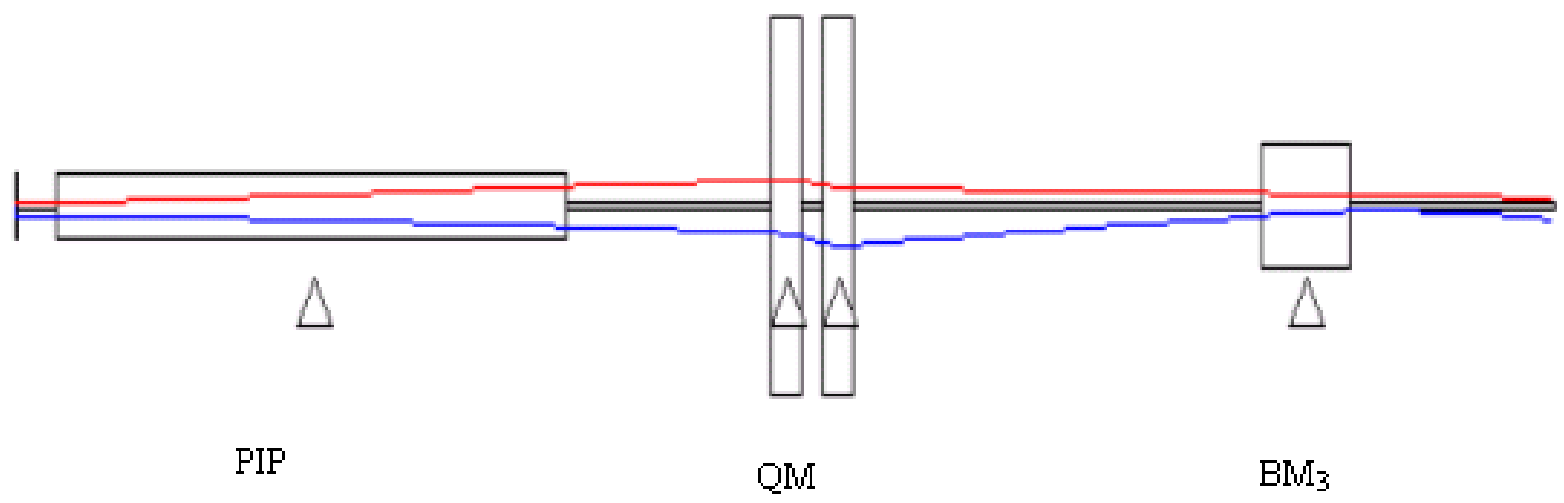

(b)

Gambar 4. Simulasi berkas ion $\mathrm{H}$ pada akselerator tandem. (a) pada pemercepat ion negatif, (b) pada pemercepat ion positif.

Diameter berkas ion hidrogen mempunyai ruji ke arah sumbu $X$ dan sumber $Y$ sebesar $1 \mathrm{~cm}$, dengan emitansi $16,5 \pi \mathrm{mm}$ mrad sesuai sumber ion jenis $\mathrm{SNICS}^{[4]}$. Supaya berkas tidak mengalami penyebaran yang menyebabkan menumbuk pada dinding tabung hanyut, maka dipasang program pembatas yaitu mem "fitting" pada pembelok pertama $\mathrm{BM}_{1}$, pembelok kedua $\mathrm{BM}_{2}$, sebelum masuk kuadrupol elektrostatik $\mathrm{QE}$ dan sebelum masuk pemercepat PIN. Dengan cara mem-fitting secara bergantian, akan diperoleh ukuran amplop berkas tidak melebihi diameter tabung hanyut, dan besarnya panjang fokus maupun medan magnet didepannya dapat diperoleh.

Hasil akhir simulasi sampai tidak ada berkas yang menumbuk dinding adalah: panjang fokus lensa einzel $\mathrm{LE}_{1}$ setelah keluar sumber ion adalah $70 \mathrm{~cm}$, masuk pembelok $\mathrm{BM}_{1} 30^{\circ}$ sebagai penyeleksi ion diperoleh jejari kelengkungan $0,533 \mathrm{~m}$ dan medan magnet $3,378 \mathrm{kG}$. Setelah keluar penyeleksi ion negatif difokuskan dengan lensa einzel $\mathrm{LE}_{2} 24 \mathrm{~cm}$ dan dibelokkan pembelok $\mathrm{BM}_{2} 90^{\circ}$ lagi untuk mengarahkan berkas ke pemercepat, diperoleh jejari kelengkungan $0,457 \mathrm{~m}$ dan medan magnet 3,489 $\mathrm{kG}$. Keluar dari pengarah berkas ion ke pemercepat dilewatkan lensa einzel $\mathrm{LE}_{3}$ dengan panjang fokus $30 \mathrm{~cm}$ untuk difokuskan dengan kuadrupole listrik QE, diperoleh hasil simulasi dengan koefisien kuadrupol 54,25 dan -89,51. Selanjutnya dengan mem-fitting pada bagian sebelum masuk pemercepat ion negatif PIN diperoleh panjang fokus lensa einzel $\mathrm{LE}_{4}$ adalah $26 \mathrm{~cm}$.

Setelah dipercepat dan melewati stripper, ion negatif berubah menjadi ion positif dipercepat dengan pemercepat ion positif PIP dan bagian ini dibuat simulasi yang hasilnya terlihat pada Gambar 4b. Ukuran berkas ion diambil dari hasil simulasi pertama. Untuk mendapatkan keluaran berkas ion diameter sekitar $3 \mathrm{~mm}$, dibuat fitting pada keluaran kuadrupol magnet.

Hasil simulasi diperoleh pemfokus kuadrupol magnet QM panjang 0,14 m masing masing dengan medan magnet pada kuadrupol 3,2 kG dan $-3,4 \mathrm{kG}$. Dan pembelok magnet diperoleh pada sudut $15^{\circ}$, jejari kelengkungan $0,833 \mathrm{~m}$ dan medan magnet $3,007 \mathrm{kG}$.

Pada Lampiran 2 ditunjukkan data-data keadaan ruji ke arah $X$ dan $Y$, divergensi serta parameter Twiss yang menyatakan arah amplop berkas, dan pada Gambar 5 ditunjukkan amplop berkas setelah keluar pemercepat ion negatif dan keadaan amplop berkas di keluaran akselerator (target).

Keadaan amplop berkas keluar dari pemercepat ion negatif (Gambar $5 a$ ) adalah ruji kearah horisontal $0,12 \mathrm{~cm}$, sudut divergensi $15,67 \mathrm{mrad}$, sedangkan parameter twiss $\alpha_{\mathrm{x}}=-8,0001, \beta_{\mathrm{x}}=0,6173$, untuk ruji ke arah vertikal $0,31 \mathrm{~cm}$, sudut divergensi 3,9 mrad, parameter twiss $\alpha_{y}=1,67, \beta_{y}=1,5471$. Selanjutnya amplop berkas pada keluaran akselerator di target (Gambar $5 \mathrm{~b}$ ) mempunyai ruji kearah horisontal $0.1120 \mathrm{~cm}$, sudut divergensi 8,54 mrad, sedangkan parameter twiss $\alpha_{x}=13,2431, \beta_{x}=4,2452$, untuk ruji ke arah vertikal $0,3231 \mathrm{~cm}$, sudut divergensi $6,329 \mathrm{mrad}$, parameter twiss $\alpha_{y}=2,4527, \beta_{y}=1,2960$.

Untuk ion nitrogen, hasil simulasi perjalanan amplop berkas dalam akselerator ditunjukkan pada Gambar 6. Perjalanan amplop berkas berkas ion mulai dari sumber ion sampai ke target dengan ruji ke arah horisontal maupun vertikal tidak melebihi diameter tabung hanyut. Karena ion nitrogen mempunyai massa lebih besar dari pada ion hidrogen, maka terdapat perbedaan besarnya medan magnet yang diperoleh dari hasil simulasi 
perjalanan amplop berkas. Pada $\mathrm{BM}_{1}$, besarnya medan magnet adalah 6,6831 $\mathrm{kG}$, untuk sudut pembelok yang sama. Sedangkan pada $\mathrm{BM}_{2}$ dan $\mathrm{BM}_{3}$ diperoleh besarnya medan magnet masing-masing adalah $34,9674 \mathrm{kG}$ dan 11,2037 kG. Sedangkkan besarnya koefisien quadrupole elektrostatik QE pada simulasi energi rendah adalah 19,2163 dan $-31,7230$, dan untuk kuadrupole magnet QM diperoleh besarnya medan magnet 3,133 dan $-3,1667 \mathrm{kG}$. Kalau dibandingkan dengan perjalanan amplop berkas antara ion hidrogen dan ion nitrogen terlihat bahwa, pada pemercepat energi rendah bentuk keluaran dengan ukuran ruji ke arah horisontal maupun vertikal hampir sama (Gambar 4 dan 6) dan besarnya medan magnet pada pembelok maupun pada kuadrupol amat berbeda. Sedangkan pada pemercepat energi medium, diperoleh ruji amplop berkas 2,5 $\mathrm{cm}$ hampir simetri baik ke arah horisontal maupun vertikal.

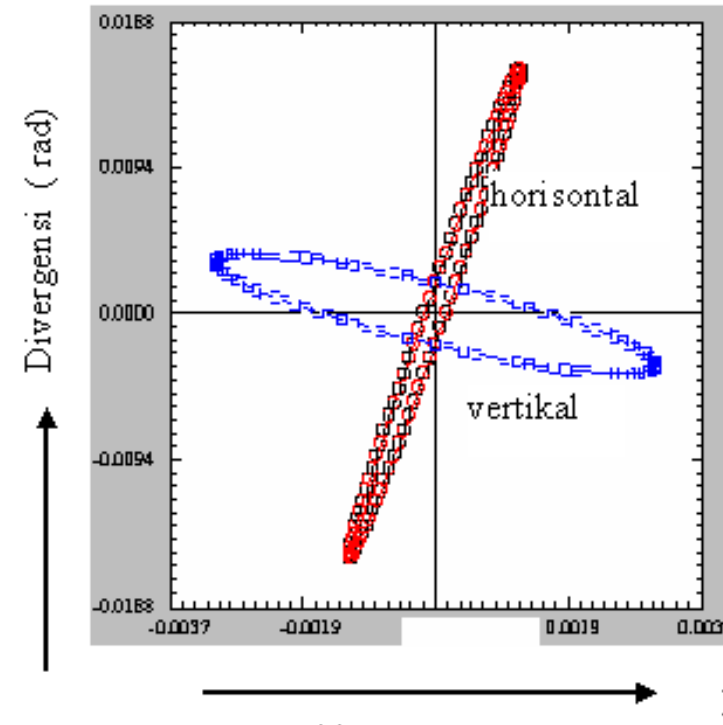

(a)

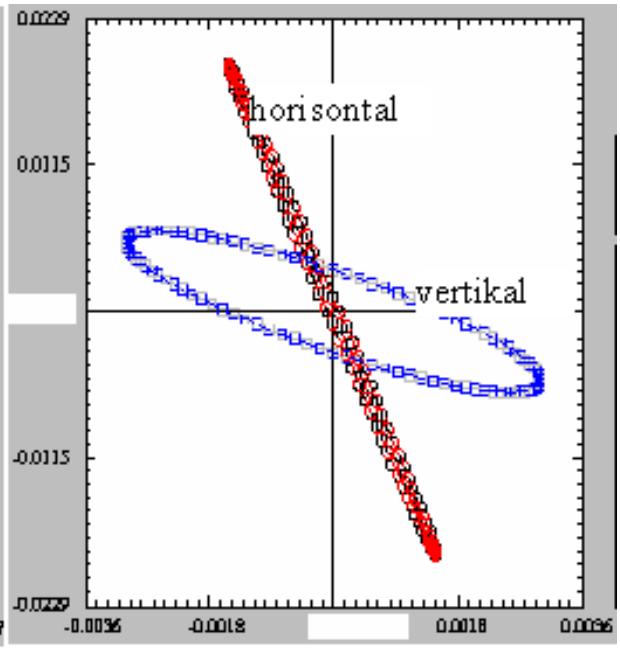

Ruji Berkasion (rr' (b)

Gambar 5. Amplop berkas ion hydrogen.
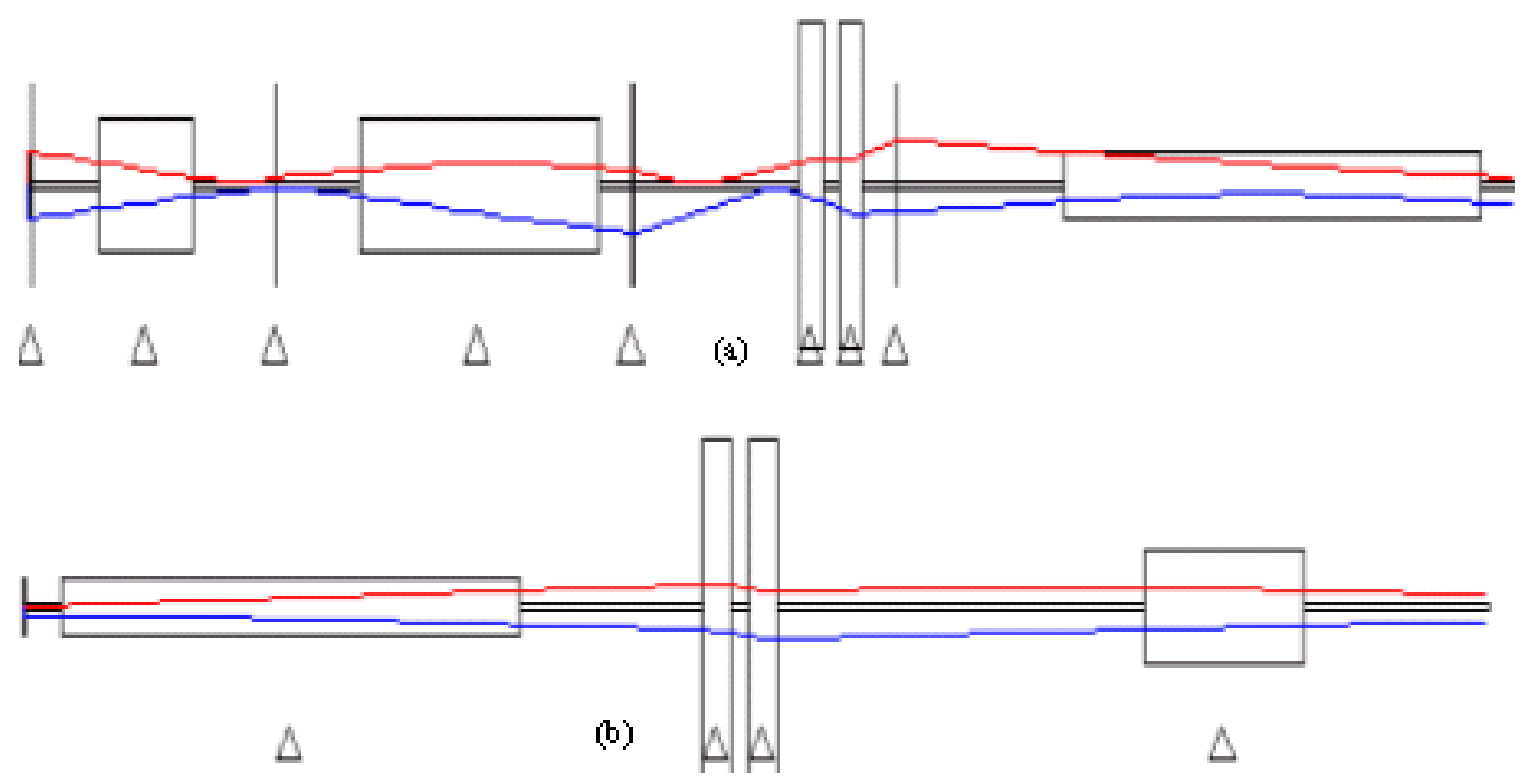

Gambar 6. Simulasi berkas ion N pada akselerator tandem. a) pada pemercepat ion negatif, b) pada pemercepat ion positif. 


\section{KESIMPULAN}

Dari hasil simulasi pengendalian amplop berkas partikel akselerator ion energi medium sampai ke target dapat disimpulkan bahwa :

- Simulasi akselerator energi medium yang terjadi dua kali pemercepatan untuk ion negatif dan ion positif dapat dilakukan dengan cara memisahkan sendiri-sendiri.

- Dengan cara mem-fitting diameter berkas pada bagian yang diperlukan, akan diperoleh besaran komponen akselerator .

- Untuk simulasi energi rendah diperlukan empat buah lensa einzel masing-masing dengan titik api $70 \mathrm{~cm}$, $24 \mathrm{~cm}, 30 \mathrm{~cm}$ dan $26 \mathrm{~cm}$, dua buah pembelok dengan medan magnet 3,378kG dan 3,89 kG, serta kuadrupol elektrosatatik dengan koefisien kuadrupol 54,25 dan $-89,51$.

\section{DAFTAR PUSTAKA}

1. GEORGE GILLESPIE, et.al., Outline of Particle Beam Optics Laboratory Tutorial Version 1.1.1, G.H. Gillespie Associates Inc. 1998.

2. BROWM, KL., et.al., Transport a Computer Program for Designing Charged Particle Beam Transport Systems, CERN Report 73-16, Geneva (1973).

3. WIEDNER C.A, Beam Transport System, Accelerator School, Center for Research and Development of Advanced Technology, 2003.

4. SHIROH KIKUCHI, SUEHIRO TAKEUCHI, A Computer Code "Beam" for the lon Optics Calculation of the JAERI Accelerator System, JAERI 1987.

5. SIGIT HARIYANTO dkk., Simulasi Alir Berkas Partikel Akselerator J 2.5 Untuk Eksperimen. 